\title{
De la profundidad a la superficie cultural. Lucha de significados y migración
}

\author{
GABRIELA CORONADO
}

Lo que los migrantes suponen sentido común proviene de la lógica cultural subyacente en comportamientos culturales aprendidos, practicados y transformados en la cotidianidad. En la nueva sociedad su cultura se ignora, pero los rasgos culturales originarios son transformados en representaciones exóticas que excluyen significados políticos y socioculturales propios. Como migrante mexicana en Australia analizo representaciones de lo mexicano para mostrar cómo se transforman y se distorsionan las significaciones culturales. Parto de la relación entre "superficie cultural" y "profundidad cultural" para explicar cómo las culturas migrantes son enajenadas al ignorar la cultura subyacente que influye en la negociación de prácticas y valores culturales.

PALABRAS CLAVE: Iógica cultural, cultura enajenada, control cultural, migración, México profundo, Australia

From Deep to Surface Culture. Struggle for Meaning and Migration

What migrants suppose is common sense is shaped by cultural logic subjacent in cultural behaviours learned, practiced and changed in everyday life. In the new society their culture is ignored but cultural elements are represented as exotic. As Mexican migrant in Australia I analyse representations of mexicanness to show how cultural meanings are transformed and distorted. Out of the relationship between "surface culture" and "deep culture" I explain how migrant cultures are alienated ignoring the underlying culture that influences the negotiations of cultural values.

KEYWORDS: cultural logic, alienated culture, cultural control, migration, Deep Mexico, Australia 


\section{Introducción}

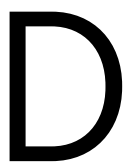

esde mi experiencia como migrante mexicana en Australia reflexiono sobre la constitución de nuestros comportamientos culturales a partir de nuestras historias en el país de origen y en el de destino. En la nueva sociedad encontramos y personificamos múltiples identidades que representan imaginarios sobre nuestra cultura y comportamientos, que se vinculan con significados profundos manifiestos o subyacentes en prácticas culturales, conocimientos y lenguaje. Para comprender dichos procesos complejos de representación cultural e identitaria es importante analizar el papel de la cultura con base en la dinámica entre dos niveles relacionados: "superficie cultural" y "profundidad cultural". Dicha distinción está inspirada en el trabajo de Guillermo Bonfil sobre las relaciones interculturales entre el México indígena y el mestizo (Bonfil, 1987b). Mi intención es ir más allá, enfatizar en el marco migratorio las dinámicas culturales y su vinculación con el marco poscolonial implícito en su teoría del control cultural (Bonfil, 1987a). Para ello exploro situaciones paradójicas que he experimentado en Australia. En particular, considero la distorsión poscolonialista de las culturas migrantes y su impacto en las estrategias de adaptación al nuevo entorno.

Utilizo un acercamiento autoetnográfico que incluye mis reflexiones sobre situaciones vividas y analizadas mediante una etnografia de la cotidianidad (Coronado, 2009; Ellis y Bochner, 2000). Para completar mi experiencia sobre las tensiones que percibo en los contextos interculturales en los que me relaciono, haré referencia a entrevistas con otros migrantes en Australia provenientes del proyecto de investigación "Cross-cultural Larrikins in a Neo-liberal World. Ideology and Myth in Postmodern Australia, Mexico and Brazil” (Hodge et al., 2010). ${ }^{1}$ Sus metas diferían de mi objetivo,

$1 \quad$ La investigación tenía por objetivo el estudio de prácticas informales desplegadas en organizaciones diversas - oficinas gubernamentales, universidades, compañías de seguros, fábricas, guarderías- para resolver problemas creados por la burocracia y la ideología empresarial. Las historias que refiero provienen de un corpus de 100 historias sobre estrategias informales y su vinculación o no con la cultura. El proyecto fue financiado por el Australian Research Council. 
pero las historias arrojan luz sobre el uso de estrategias culturales de los migrantes latinoamericanos para adaptarse al medio australiano y la imaginada contribución de su cultura subyacente. Paradójicamente, las diferencias percibidas fueron al mismo tiempo estrategias presentes en otras culturas, en particular en este caso el estilo australiano representado en la figura icónica del Larrikin, a la cual me referiré más adelante. Al explorar estas experiencias, en la misma línea que Cohen, considero que cada historia es idiosincrática, pero "al mismo tiempo única y típica y como tal revela algunas de las complejidades de la experiencia migratoria en sí" (Cohen, 2004: 130). ${ }^{2}$ A continuación analizo algunas de mis experiencias con el fin de ilustrar el marco conceptual mencionado.

\section{Complejidad de las dinámicas culturales y sus representaciones}

En este trabajo parto de la convicción de que la cultura profunda de los migrantes constituye un recurso cultural implícito en la interacción en contextos multiculturales laborales y sociales. Aunque esta cultura subyacente no se reconozca siempre, e incluso sea rechazada ideológicamente, los valores contenidos en la lógica cultural influyen en cómo participan los migrantes en el nuevo país. Para comprender la complejidad de la dinámica cultural en los movimientos entre país de origen y país de destino es relevante concebir a las culturas como sistemas complejos en continua renovación y recreación de significados (Hannerz, 1992). Esta dinámica no implica la pérdida de su identidad con el pasado, sus significados se encadenan en conexiones íntimas con principios culturales fundamentales, derivados de un “' plano general' o matriz cultural, específica a cada cultura y cambiante en el devenir histórico, que articula y da sentido a los diversos elementos" (Bonfil, 1987a: 27). Las culturas cambian al mismo tiempo que mantienen su identidad.
Una metáfora útil para entender el concepto de matriz cultural proviene del vínculo entre la lengua y la cultura como sistemas semióticos (Geertz, 1987). La matriz cultural es la "gramática" de las culturas de donde emergen y se estructuran las formas en las que los significados se realizan. A partir de ella prácticas y significados culturales son creados, transformados y apropiados por sus productores como respuesta a procesos en los que los significados son negociados, expropiados o impuestos por agentes de otras culturas. Este proceso implica transformaciones de los significados y prácticas culturales generadas desde la matriz cultural en un nivel profundo. Si bien los productos generados pueden variar en sus manifestaciones en la superficie cultural, conllevan significados que sus portadores comparten. La matriz cultural es el poder generativo desde el cual se transmiten significados culturales que son heredados a las siguientes generaciones y al mismo tiempo es la base para la respuesta a las condiciones y necesidades cambiantes de la sociedad. De este proceso generativo surgen diversas manifestaciones como respuesta a dinámicas intra e interculturales históricas, económicas, políticas y sociales. Algunas de estas prácticas son compartidas por varios grupos y otras se utilizan en contextos circunscritos, identificados con las necesidades locales. Las representaciones de otras culturas pueden ser concebidas con exclusión de la agencia de los "dueños" culturales, es decir enajenadas o producidas bajo su control cultural (Bonfil, 1987a).

La producción y reproducción de la cultura son en sí mismas un proceso intercultural, pero en el entorno cultural y lingüístico de la migración la interculturalidad se multiplica e influye cotidianamente en el quehacer cultural de los migrantes. En

"Both unique and typical and as such reveals some of the complexities of the migratory experience itself" [todas las traducciones son propias, n. de la a.]. 
estas interrelaciones los migrantes actúan de manera diferente, al mismo tiempo que persiste el sustrato cultural. En él la lengua juega un papel importante en el proceso de hacer sentido del mundo circundante, de relacionarse y comunicarse con los demás. La lengua y la cultura como redes semióticas interdependientes están implicadas en la generación de una lógica cultural profunda, una manera de "mirar" y concebir la realidad circundante. Esta lógica supone un modelo cultural (Holland y Quinn, 1987) en el que la o las lenguas dan forma a maneras de pensar y actuar. A través de patrones de lenguaje, estructuras gramaticales, clasificaciones semánticas y redes con otros códigos semióticos — por ejemplo, ideológicos- constituimos nuestra lógica y nuestro sentido común, con base en ellos interpretamos los significados producidos en la comunicación con otros hablantes (Kramsch, 2008). Nuestra cultura se expresa en las palabras en uso y en complejos patrones de significado, que incluyen valores, creencias e ideologías (Hodge y Kress, 1993). Esto no implica necesariamente la conciencia cotidiana de los hablantes, pero aun así nuestra lengua materna nos constituye y da sentido colectivo a nuestras maneras de hacer cultura. A través de su gramática y lógica cultural subyacente la lengua guía nuestra forma de mirar, pensar y actuar en el mundo. Al migrar trasladamos nuestra lógica cultural subyacente e incorporamos a ella nuevas lógicas culturales aprendidas en la nueva lengua y prácticas que encontramos en el nuevo entorno.

En el contexto migratorio, cuando se identifican prácticas culturales específicas como representativas de una cultura y son adaptadas a nuevos contextos, se re-significan, pierden total o parcialmente su significado original y adquieren otros. En muchos casos, las manifestaciones culturales no están bajo el control de sus agentes y fácilmente excluyen los significados subyacentes que identifican a los migrantes con su cultura de origen. En estas situaciones es posible ver esas prácticas como manifestaciones de la cultura de la superficie, parcialmente o en gran parte desconectadas de los significados originarios. En los términos propuestos por Bonfil (1987a: 29), se convierten en cultura enajenada, en la que si bien algunos elementos son propios, sus portadores son excluidos de las decisiones sobre su uso y significación.

El proceso de enajenación no es exclusivo de la movilidad cultural transnacional. Aparece también en países en situaciones poscoloniales que "orientalizan" (Said, 1978) las culturas originarias y las representan con ideologías colonialistas como primitivas, exóticas - por ejemplo, en el ámbito del turismo (Coronado, 2004) - En ambas situaciones los portadores de la cultura pierden el control cultural, es decir, la capacidad de participar en la toma de decisiones sobre los elementos culturales (Bonfil, 1987a: 28). En este caso exploraré este proceso en la migración internacional, en la que las culturas de los migrantes son enajenadas y representadas mediante actitudes poscolonialistas, implícitas en ideologías interculturales globales (Coronado, 2012; Prasad, 2012).

\section{El imaginario exótico de la cultura mexicana}

$\mathrm{Al}$ inicio de mis investigaciones sobre la representación de los mexicanos en Australia encontré que el imaginario está colmado de estereotipos o, en el mejor de los casos, de representaciones folclóricas que retoman elementos de la superficie cultural y los interpretan en un marco de significación diferente. Por lo general, las representaciones culturales provienen de comportamientos que son parte de la cultura originaria y llevan significados a través de su práctica, pero cuando se encuentran fuera de su contexto es común que se ignoren sus significados subyacentes y que se conviertan fácilmente en imágenes exóticas representativas de la cultura en cuestión. Los migrantes estamos expuestos con 


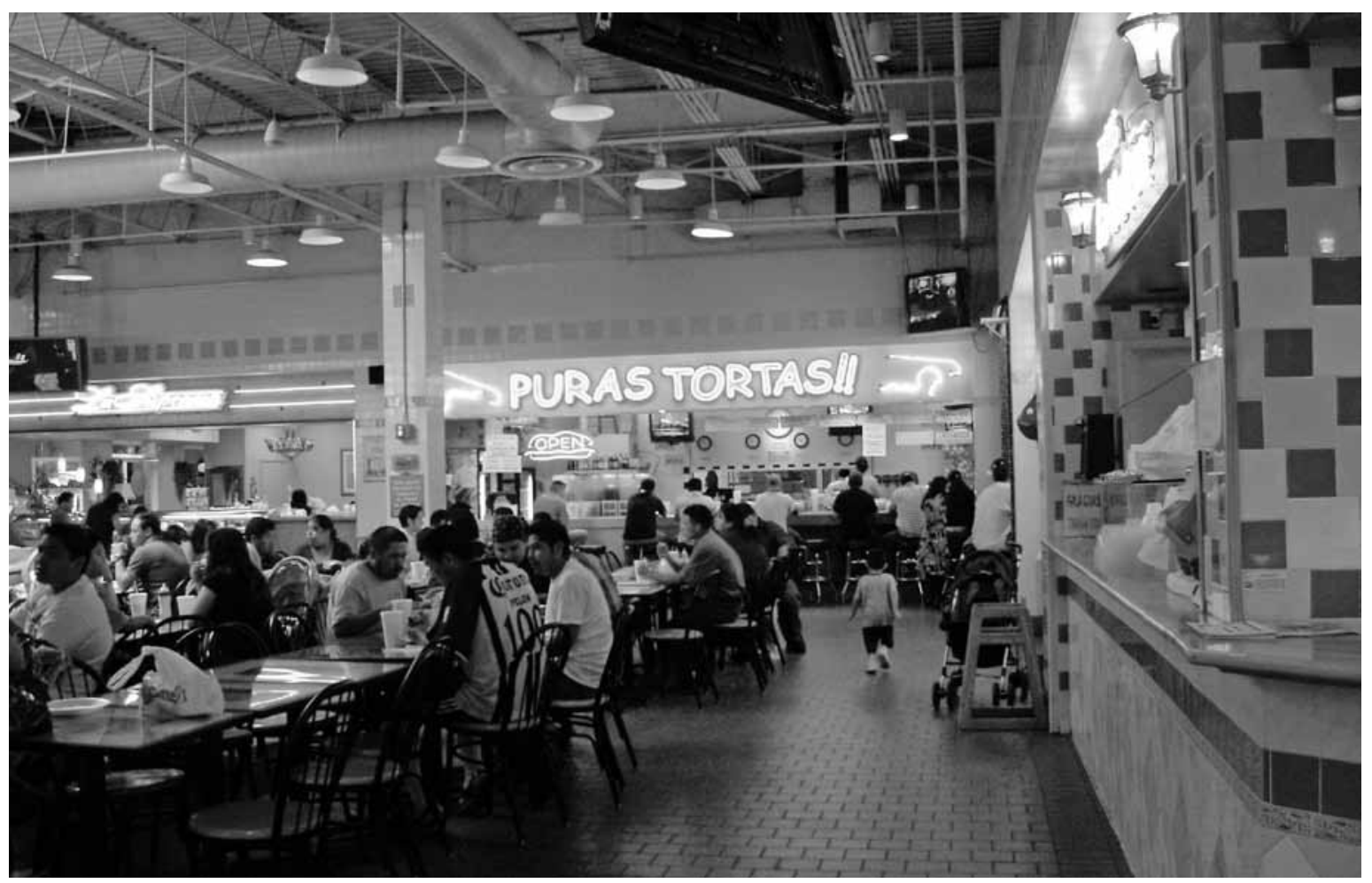

PATRICIA FoRTUnY $\bullet$ Una muestra de lugares frecuentados por los inmigrantes latinos en Atlanta, Georgia, abril 2008.

frecuencia a estas falsificaciones de la superficie cultural que eliminan nuestros significados culturales profundos. La siguiente frase de un migrante mexicano ilustra nuestra frustración ante dichas situaciones: "¿Mexicano? Luego, luego te ven con cara de tequila y fiesta" (Mexoz081105). ${ }^{3}$ Eso no significa que las representaciones no conlleven significados. Las manifestaciones son re-significadas e incluyen, aunque no necesariamente, actitudes discriminatorias.

En mi opinión, es obvio que para los australianos de diferentes culturas — dada la multiculturalidad del país - las representaciones más comunes de México incluyen los sombreros que se ven en las tribunas de futbol, de mariachi o de charro, la llamada comida mexicana - tex-mex-, el tequila y las margaritas. Los anuncios en los medios de comunicación exotizan la cultura mexicana como rural, asociada todavía a las representaciones de la década de
1950 en el cine mexicano. Un ejemplo es la marca El Paso que promociona sus productos como "comida mexicana". En un anuncio de marzo de 2013, una niña campesina es levantada en hombros por sugerir la invención de una salsa sin chile. En otras escenas se observan escenarios de haciendas con charros, burros con sombrero y otras historias sobre invenciones hechas por la misma niña: "tostadas con base plana para que no se caiga el relleno", dobladas en forma de "U" en lugar de "V" (septiembre de 2012). La lucha libre también aparece en otras representaciones, como en un anuncio televisivo de Doritos Australia que presenta a otro

3

Uso este código como referencia a la identidad del entrevistado. Las entrevistas fueron hechas en Australia, clave oz, y los números indican la fecha. 
personaje mexicano: un luchador enmascarado. Utilizaré este mensaje publicitario para ilustrar la de/resignificación de la cultura profunda en la representación de la superficie cultural en el contexto australiano. No intento hacer un análisis exhaustivo de la lucha libre sino señalar cómo los significados profundos de la cultura en México se transforman en superficie cultural en Australia y de ahí en estereotipo.

\section{La batalla de los sentidos}

La lucha libre ha sido popular en México desde que recuerdo. Mi abuelo solía ir a las luchas cuando yo era niña. Este entretenimiento se ha identificado como un intento de crear iconos de identidad urbana, inexistentes al inicio de la urbanización de la sociedad mexicana (Fernández, 2004). Algunos luchadores se hicieron famosos, pero El Santo, el "Enmascarado de Plata", se considera el único héroe de América Latina a escala mundial (Mego, 2007). Entre 1958 y 1982 El Santo fue protagonista de 53 películas en las que luchaba contra las fuerzas del mal (Carro, 1984). El estatus de la lucha libre ha cambiado. De ser una actividad popular entre los migrantes rurales urbanizados, como mi abuelo, se ha puesto en boga en otros sectores. En la ciudad de México empezó a ser una actividad de moda entre jóvenes de otros estatus. Este cambio implica ya una resignificación de su valor social y cultural, una transformación de la cultura profunda hacia su manifestación en la superficie que conlleva significados comunes y particulares para las diversas audiencias. La moda de los luchadores también muestra su éxito comercial tanto en mercados mexicanos como internacionales. ${ }^{4}$ Un indicador de su relevancia en México son las tiendas de productos oficiales de luchadores famosos: "El Hijo del Santo" en la ciudad de México, con sucursal en el Aeropuerto Internacional y en internet, y "Blue Demon Jr." en las ciudades de México, Guadalajara y en línea.
Puesto que la lucha libre en México se vincula con la cultura diaria y ritual de la sociedad mexicana, es razonable suponer que contiene significados relevantes para sus productores y seguidores. Como otras prácticas con bagaje histórico, las luchas llevan mensajes que se conectan con valores culturales existentes en y vinculados con otras prácticas simbólicas. Según Levi, la lucha libre como espectáculo cultural representa un conjunto de símbolos asociados a otros aspectos de la cultura y la política mexicana: "tiene sentido porque es un género teatral que aprovecha y reproduce una serie de contradicciones que son ampliamente inteligibles en el contexto de los antecedentes históricos y culturales compartidos por sus fans mexicanos" (Levi, 2008: xiii). ${ }^{5}$

Su vinculación con las culturas rurales sugiere la continuidad de significados provenientes de otras actividades rituales que al trasladarse al contexto urbano fueron incorporados. Es decir, lo que emergió en la superficie de este fenómeno cultural resignifica significados originarios. Es factible que haya una conexión con las danzas tradicionales. En algunas comunidades rurales, indígenas y mestizas, las danzas juegan un papel importante en la vida sociopolítica y ritual. Algunas representan luchas simbólicas y en muchas se usan máscaras que representan al bien y al mal (Coronado, 2003b). ${ }^{6}$ En la migración sus significados profundos pudieron trasladarse, mantener subyacentes las tradiciones de lucha en el campo y ser adaptados como entretenimiento en las ciudades. Mi interpretación es que las danzas representan la combatividad, muchas veces reprimida, de las sociedades rurales mestizas e indígenas. La lucha

\footnotetext{
$4 \quad$ Es popular en otros países, como Estados Unidos y Japón. $5 \quad$ "Makes sense because it is a performance genre that draws on and reproduces a series of contradictions that are broadly intelligible in the context of the shared historical and cultural background of its Mexican fans".

$6 \quad$ La importancia de las máscaras en la cultura mexicana
} también es resaltada por Levi (2008). 
libre traslada dicha tradición combativa a los espacios urbanos. Cuando las representaciones culturales se trasladan a otros países, su significación puede perderse. Se extraen de ellas significados asumidos y otros son incorporados para convertirse en una cultura diferente a la originaria.

Este proceso de resignificación puede apreciarse en el anuncio televisivo de Doritos (mayo-junio de 2011). La campaña, destinada a informar a los consumidores que pueden elegir el sabor para un nuevo producto, presenta a un luchador mexicano peleando contra uno tailandés. En la representación de ambos personajes es evidente la construcción exótica que, si bien muestra elementos culturales existentes en los países de origen, descontextualiza y extrae sus significados para convertirla en cultura enajenada. Las representaciones no sólo son caricaturas, sino que incorporan otros significados que deliberadamente o no influyen sobre la aceptación o rechazo de los productos y por extensión de las culturas.

En internet, la competencia entre la picante salsa mexicana y el chile dulce tailandés, llamada "Batalla de los Sabores" — "Battle of the Flavours"-, se enlaza a la página web de la empresa. Ahí se ofrecía información detallada y videoclips que, si bien son mercadotecnia, representan imaginarios culturales asociados a sectores de la población que han emigrado a Australia. El siguiente fragmento de la promoción de la competencia muestra elementos de este imaginario:

Señoras y señores, empieza la Batalla de los Sabores de Doritos. En la esquina verde, contamos con la salsa mexicana picante. En la esquina roja, con thai chile dulce. Dos nuevos sabores, uno saldrá victorioso y el otro será derrotado. Para asegurar una batalla limpia, tú decides qué sabor gana y se queda en el estante. ¿Qué te parece? Compra estos dos nuevos sabores de Doritos, pruébalos, dinos cuál es el mejor y puedes ganar un gran momento... Es una pelea, ¿de acuerdo? ¡Así que habrá muchísima acción en esta grandiosa batalla! Puedes apostarlo. Instruye a El Macho para patear al tailandés Phoon y lo hará. Instruye al tailandés Phoon para que le pellizque los pezones o le dé a El Macho un golpe bajo y felizmente obedecerá. Diles lo que quieras y lo harán. Pero esto se pone todavía mejor pues mientras ellos luchan, tú ganas. [...] Sube en línea movimientos de batalla que no hemos filmado... Piensa en grandes movimientos, graciosos o totalmente estúpidos. Mientras más entretenidos, mejor. ${ }^{7}$

Después apareció otro anuncio en la televisión (18 de agosto de 2011) y sentí alivio al saber que El Macho, la salsa mexicana picante, había perdido. Algunos videoclips caricaturizaban su derrota, pero eso no disminuía la inaceptable imagen del otro luchador y su cultura. No era menos ridícula por ser campeón. ${ }^{8}$ Como migrante mexicana me sentí avergonzada por la manera en que mi cultura originaria era denigrada en público en mi lugar de residencia. Me alegró saber que mis amigos no lo

7

“Ladies and gentlemen, it's Doritos' Battle of the Flavours. In the green corner, we have Hot Mexican Salsa. In the red corner, Thai Sweet Chilli. Two new flavours, one's hanging around and the other's going down. To ensure a good clean battle, you decide which flavour wins and stays on shelf. How good is this? Buy these two new Doritos flavours, taste them, and then tell us which one is best and you can win big time... It's a battle, right? So there's going to be lots of great battling action. You bet. Instruct El Macho to kick Thai-phoon and he will. Instruct Thai-phoon to nipple-cripple, wedgie or punch El Macho and he will happily oblige. You name it; they'll do it. But it gets better, because while they do the battling, you do the winning. [...] Come up with battle moves that we haven't filmed... Think big moves, funny moves or totally stupid moves; the more entertaining the better".

8 Aunque es común el uso de bromas en anuncios comerciales y esta representación pudiera interpretarse sólo como humor inocente, en contextos interculturales es altamente riesgoso burlarse de otras culturas, puede interpretarse como ocultamiento de sentimientos chovinistas. 
vieron, pero preferiría que dichos estereotipos desaparecieran por completo.

En la nueva sociedad los estereotipos nacionales se extienden ampliamente y la exótica versión de la superficie cultural, vaciada de sus significados, homogeneiza a los latinoamericanos. La descontextualización de las prácticas culturales provenientes de nuestros países y la extracción de sus significados profundos están en el centro de las formas poscolonialistas de expropiación de las culturas (Said, 1978). Estas representaciones generan, además, falsas expectativas sobre comportamientos que distan mucho de nuestra experiencia en nuestros países de origen y tampoco son significativos en el nuevo entorno (Coronado, 2003a).

\section{La cultura subyacente en la migración de chilanga a aussie}

Como migrante es difícil para mí dominar las tensiones entre mis identidades pasadas y las nuevas. Me veo confrontada por formas en las que ser mexicano o latinoamericano tiene un sentido diferente. En México nadie espera que seamos lo mismo sólo por ser mexicanos. Además, los aspectos más salientes de nuestras identidades son las idiosincrasias regionales, étnicas o de clase. En México me identifico como chilanga — de la ciudad de México-y me considero diferente a los de otras ciudades. Me distingo también de los mexicanos del campo, quienes a su vez se identifican o no como indígenas. La identidad latinoamericana también varía y no siempre implica que nos identifiquemos como tales. Aun si lo hacemos, esta identidad ha cambiado con el tiempo. Nos movemos continuamente entre ser orgullosos latinoamericanos y orgullosos nacionalistas, críticos de otros pueblos de América Latina. Yo me sentía más latinoamericana en los años setenta del siglo pasado cuando la música de protesta contra las dictaduras se popularizó en México o cuando
Estados Unidos intervenía en un país de América Latina. Asimismo, existen conflictos asociados a historias nacionales y experiencias personales, y entre países y dentro de ellos las formas culturales son diversas.

Estas complejidades se trasladan al nuevo contexto, pero se minimizan las diferencias en razón de la alteridad. En Australia nos asemejamos en la medida en que nos distinguimos de otras culturas y vemos que nuestras costumbres y comportamientos tienen mucho en común. Al migrar a Australia, descubrí que algunas costumbres, historias e incluso frases que solía creer que eran muy mexicanas son las mismas en otros países. Por ejemplo, Cohen (2004: 127) menciona el dicho salvadoreño "Cada cabeza es un mundo", que siempre consideré mexicano.

También compartimos un lenguaje y a pesar de los dialectos nos comunicamos fácilmente. Por último, compartimos, tanto allá como acá, nuestra identidad como no anglosajones. Esta identidad es relevante en ambos contextos. En Latinoamérica conlleva ideologías y políticas antiimperialistas que nos vinculan dado que muchos migrantes tienen calidad de refugiados, consecuencia de las dictaduras apoyadas por Estados Unidos. No es el caso de la migración mexicana; sin embargo, me resulta confortable compartir dicha identidad. En Australia no somos antianglos, pero nos identificamos como latinoamericanistas prorrevolucionarios. Como menciona Liliana Correa, la expectativa en Australia era ésa y los migrantes le dieron la bienvenida:

Tuve mis primeros encuentros con otros latinos y ahí descubrí la posibilidad de rehacernos a nosotros mismos por completo. No había manera de que los hechos discutidos fueran corroborados por alguien. No había razón para dudar de cualquier historia contada... Teníamos a todos, los Víctor Jaras y los Che Guevaras, verdaderos protagonistas de causas revolucionarias puramente por nuestra capacidad de reinventarnos a nosotros mismos y 
gracias a tanta licencia poética y realismo mágico representamos, nos disfrazamos y actuamos esos papeles (Correa, 2010: 15-16). ${ }^{9}$

La migración cambia nuestras identidades y el modo de imaginarnos en el país de la nueva ciudadanía. Las razones de la migración, lo que dejamos atrás y nuestra nueva vida en otro lugar, idioma y cultura, crean una diversidad de maneras de ser, identificarse y comportarse (Duarte, 2005). Como latinoamericanos nos sentimos diferentes entre nosotros y a menudo nos quejamos de que nos vean como si fuéramos lo mismo. En contra de las representaciones de otredad que nos homogeneizan, subrayamos las diferencias y tendemos a ignorar las similitudes (Jenkins, 1997). Sí, tenemos muchas diferencias en la superficie, pero al parecer compartimos una profundidad cultural que hemos transportado a nuestra nueva vida y que utilizamos para relacionarnos, entendernos, comunicarnos y actuar en el nuevo entorno social.

Esta lógica cultural no es necesariamente consciente. Nos constituye y subyace en nuestros hábitos, creencias, conocimientos, valores e ideologías. Lo que creemos acerca de nosotros mismos interactúa con lo que los anglos esperan, ya sea real o en nuestra imaginación (Bakhtin, 1996). Estos diálogos nos transforman y nos diferencian de lo que éramos antes de migrar. Es decir, concebimos nuestras identidades y comportamientos culturales de maneras no conscientes antes de la experiencia intercultural, en este proceso reflexionamos sobre la alteridad y asumimos que nuestras conductas provienen de nuestro bagaje cultural. En el siguiente comentario sobre el contraste entre mexicanos y angloaustralianos un mexicano emigrado a Australia ilustra esta convicción:

el mexicano es ingenioso por naturaleza, el mexicano busca alternativas, les das [a estudiantes de ingeniería] el ejemplo de que para arreglar el vocho [vw] todo lo que uno necesitaba era una lata de Tecate, lo que sea [...] nos gusta tanto el fix problema, el arreglar el problema, y tener la satisfacción de haberlo arreglado..., quién sabe cómo lo arreglaste, a lo mejor con una cintita, con un hilito, con lo que tú quieras (Mexoz141205).

Reconozco esta representación de la mexicanidad que incorpora lo expresado en otras historias sobre cómo los latinoamericanos perciben su diferencia en Australia: una cualidad individual influida por circunstancias e historias socioculturales generadas a partir de la cultura de origen.

Como emigrantes, al vivir en otra cultura y lengua estamos expuestos a otras formas de organizar y descifrar significados. No obstante, los significados profundos de nuestra cultura y lengua se mantienen implícitos. Prevalece la lógica cultural subyacente en la primera lengua, incluso si uno se integra plenamente al país de destino y la segunda lengua es el principal medio de interacción cotidiana. Vivo en el idioma de los "otros", pero lo hablo pensando en español: los hablantes bilingües "pueden 'silenciar' uno de sus idiomas, pero no pueden 'apagarlo' totalmente”, como afirma Treffers-Daller (2009: 63). ${ }^{10}$

Quisiera sugerir, al extender esta noción hacia otras prácticas culturales, que la persistencia del sustrato lingüístico y cultural moldea la lógica de los procesos cognitivos y las formas de actuar y hacer

9

"Have my first encounters with other Latinos who made me realised about the possibility of remaking oneself entirely - no chance that facts discussed were going to be corroborated by anyone. No reason to doubt any story told... We had them all, the Victor Jaras and Che Guevaras, true protagonists of revolutionary causes purely by our capacity to re-invent ourselves and thanks to so much poetic license and magic realism - we played, dressed and acted the roles".

10 "Can 'turn down' one of their languages, but that they cannot completely 'turn off' that language". 
sentido. Explicar cómo la lógica profunda del idioma interactúa con otras lógicas culturales y cuáles son sus implicaciones me supera y sólo puedo referirme a ello al reflexionar sobre la incómoda sensación que experimento cuando se evidencia que los hablantes de otros idiomas y culturas asumen algo como lógico, sentido común, diferente de lo que yo he dado por sentado. El siguiente comentario expresa un sentimiento similar: "Qué regla es estúpida es relativo. Porque quizá una regla que es estúpida para mí no lo es para un australiano porque están acostumbrados a vivir bajo ella, pero cuando uno viene de otro país, lo que uno cree es sentido común pudiera no serlo" (Mexoz031005).

La existencia de múltiples lógicas culturales involucra una enorme riqueza cultural con una diversidad de maneras de pensar el mundo. Entonces me pregunto: ¿qué tan importantes son las culturas de los migrantes en el contexto multicultural australiano? A continuación exploraré dicha valoración a partir de la consideración de la persistencia de la profundidad cultural en el nuevo contexto y de la reflexión sobre los procesos de negociación de significados en los que nos enfrascamos día a día.

\section{El imaginario migrante y sus "luchas" en el contexto laboral}

Una característica importante del lugar de trabajo australiano es su diversidad multicultural. Aunque las políticas del multiculturalismo han influido en la aceptación de una diversidad de prácticas culturales, también hay expectativas de que los migrantes se ajusten al estilo angloaustraliano (Langer, 1990). En efecto, las diferencias culturales se hacen invisibles y

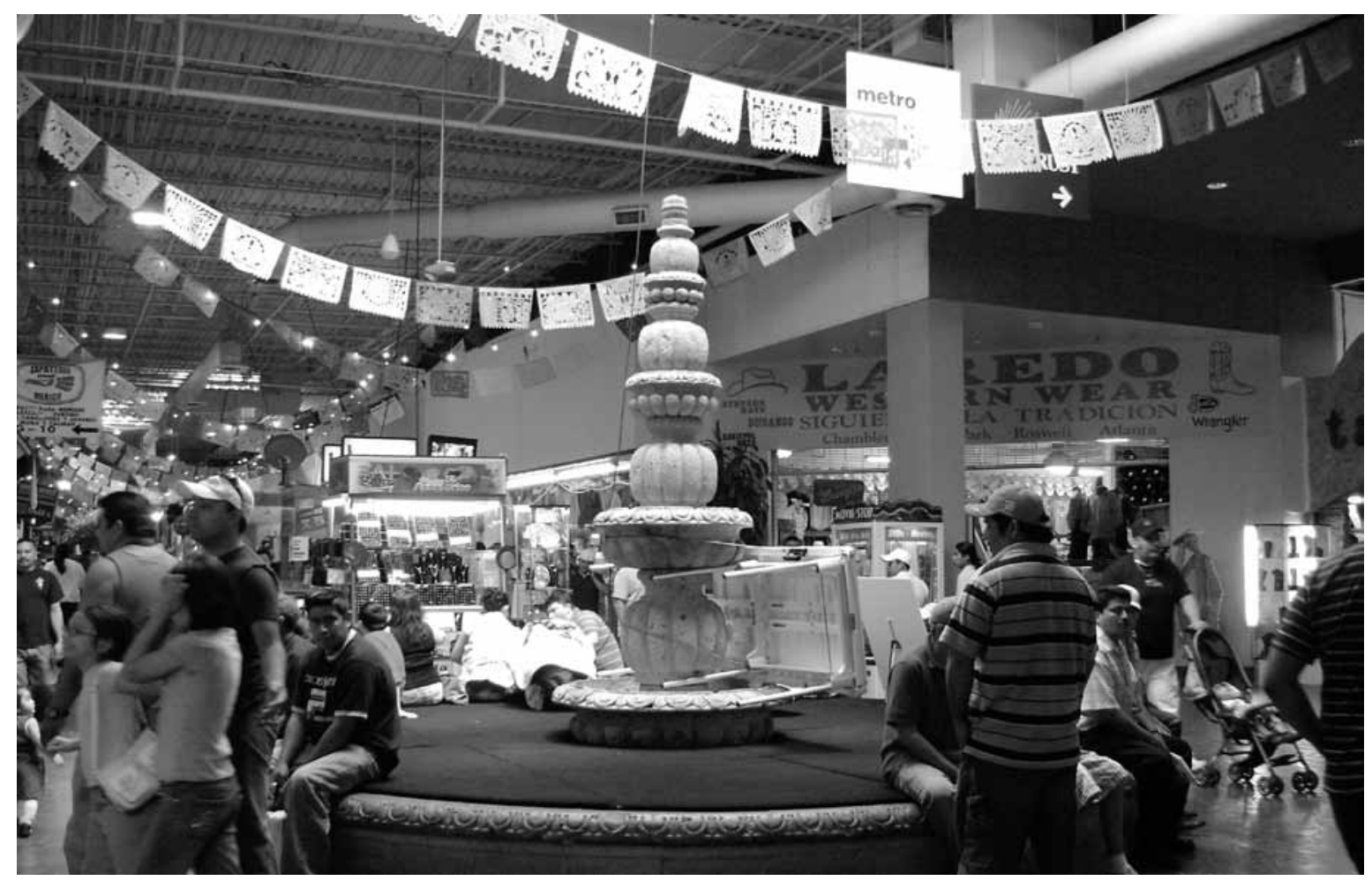

Patricia Fortuny Plaza Fiesta, Atlanta, Georgia, 2007. 
formas culturales laborales son en su mayoría disimuladas, de modo que podemos operar en nuestros trabajos sin despertar sospechas. Al mismo tiempo que estas diferencias se ocultan, representaciones de la cultura superficial y estereotipos son evidentes (Stratton y Ang, 1998). En el nuevo entorno tendemos a modelar nuestros comportamientos para ser aceptados e incluso tratamos de parecer más australianos que el australiano. Cuando se acentúan las diferencias culturales en contextos organizativos es para resaltar que son un problema (Holden, 2002) y por tanto las posibles contribuciones o similitudes son fácilmente ignoradas. En la práctica diaria, sin embargo, las organizaciones funcionan de manera más compleja, con interacciones sociales y diversidad cultural que se filtran en las prácticas de trabajo. Los estilos culturales pueden ser invisibles o deliberadamente ocultados, pero son parte de cómo funcionan las oficinas multiculturales. A continuación examinaré estrategias interculturales en la vida laboral con base en las diferencias y similitudes reportadas por migrantes en Australia, en particular respecto de la llamada cultura anglo-celta. Mi objetivo es enfatizar sus percepciones sobre la contribución de la especificidad cultural y en segundo término vincular dichas prácticas con fenómenos similares en otras culturas.

\section{Alianza entre El Santo y Cocodrilo Dundee}

Los narradores hicieron referencia a su experiencia intercultural que refleja la multiculturalidad de los lugares de trabajo australianos. También mencionaron recuerdos o imaginarios sobre las estrategias informales en sus países de origen y cómo éstas cambiaron o no en la nueva cotidianidad. Algunos comportamientos atribuidos a su cultura fueron interpretados como producto de las luchas por la supervivencia en el país de origen: se rompen las reglas como la única manera de hacer las cosas.
Puedes hacerlo si lo necesitas, pero sólo si careces de cualquier otro medio; si no necesitas estos comportamientos en el nuevo contexto, los mantienes latentes, pues también acá pueden ser útiles.

Estas percepciones me permiten interpretar dichas prácticas como habilidades derivadas de la profundidad cultural de los migrantes, que al parecer coinciden con prácticas informales en otras culturas. No obstante, su valoración cambia según el contexto y la adjudicación identitaria. Por ejemplo, historias similares recogidas en Australia y México sobre el control de fotocopias mediante cuotas mensuales relatan cómo lograron superar las restricciones cuando la demanda fue mayor y la aplicación de la regla era inflexible. En el contexto australiano estas estrategias fueron apreciadas como una cualidad orgullosa de ser australiano, larrikin, pero no fue así en el contexto mexicano, en el que podían catalogarse como tramposas o corruptas. Ambos casos coincidieron en la satisfacción por derrotar la irracionalidad del sistema.

Los empleados latinoamericanos eran los héroes en las narraciones y se imaginaban a sí mismos como los más flexibles, mientras que sus jefes anglos eran percibidos como rígidos. Por su parte los entrevistados anglos también aparecían como héroes y sus jefes, sin importar su origen cultural, irracionalmente rígidos. Las similitudes pudieran vincularse a la historia migratoria australiana, en la que varias oleadas migratorias han conformado el carácter multicultural de la sociedad (Castles y Vasta, 2004; Hodge y O'Carroll, 2006), y lo que ha influido en cierto grado en las diferentes culturas. Es posible sugerir alternativamente la existencia de estrategias laborales compartidas que, fuera de la especificidad cultural de su origen, permiten resolver problemas, innovar y en última instancia ignorar las reglas que obstaculizan su trabajo. Los narradores interculturales, es decir, australianos de diferentes culturas, coincidieron en su rechazo a las formas rígidas de autoridad y control, pero interpretaron 
sus respuestas ante ello de maneras diferentes. En tanto que los latinoamericanos desde sus orígenes culturales catalogaron su comportamiento heroico como estrategias de sobrevivencia aprendidas, los angloaustralianos bromeaban acerca de su identidad y se autorrepresentaban con los estereotipos del llamado larrikin.

Casualmente, el personaje del larrikin comparte con los luchadores su emergencia como parte de las identidades formadas durante los procesos de urbanización. Esta identidad se popularizó a finales del siglo XIX y principios del xx para referirse a los jóvenes bravucones o sinvergüenzas de la subcultura de la pobreza en las urbes. El término se aplicaba a trabajadores esporádicos, adolescentes y adultos jóvenes que se unían en pandillas, peleaban entre sí y desafiaban y ridiculizaban a las autoridades. ${ }^{11} \mathrm{La}$ expresión todavía se utiliza en Australia para caracterizar comportamientos estereotípicos cómicos o extravagantes. Como personaje se asocia con el estilo representado, por ejemplo, en la película Cocodrilo Dundee. Otras asociaciones incluyen al bandolero Ned Kelly — ahora considerado héroe- e incluso a personajes políticos como el exprimer ministro Bob Hawke. Según Bellanta (2012), ser larrikin en la actualidad tiene connotaciones positivas y esta percepción es confirmada en las historias de nuestros narradores.

Al reflexionar sobre las historias y la convicción de los narradores acerca de que sus comportamientos provenían de sus culturas originarias, los mexicanos mencionaron personajes culturales del cine y la televisión, como el Milusos, Cantinflas y Súper Barrio, activista político disfrazado de luchador (Levi, 2008). Estas referencias sugieren asociaciones simbólicas con el pícaro, el embaucador, el "coyote" o trickster, un arquetipo representado en muchas culturas como una criatura astuta que puede ser hombre o mujer, divina, humana o animal (Jung, 2004). Según Ballinger, "el epíteto trickster también se ha aplicado a algunos héroes de la cultura popular y a los personajes euroamericanos literarios, como el bandolero romántico, el estafador y en particular el novelesco pícaro" (Ballinger, 1991-1992: 21). ${ }^{12}$

Aunque el significado cultural de los arquetipos del trickster es complejo, juegan papeles particulares y tienen significados locales, comparten rasgos comunes asociados con estrategias de supervivencia en condiciones adversas. Esta base cultural profunda, compartida por muchas culturas, y el papel simbólico que desempeña inducen a interpretar que las prácticas informales de trabajo atribuidas a embaucadores en diferentes culturas pudieran provenir de comportamientos culturales comunes. Según esta hipótesis, una explicación de la convergencia se relaciona con el contexto de las relaciones de poder en las historias de las culturas. En la mayoría de los casos las culturas provienen de procesos con profundidad histórica en los que las culturas han tenido que adaptarse a situaciones adversas, por ejemplo, colonialistas, y generar procesos de resistencia ante la opresión. Es decir, las historias de las culturas son luchas por el control y la libertad.

Cada trickster cultural tiene profundas raíces históricas y despierta reacciones ambivalentes según diferentes épocas, contextos sociales y lugares. Lo que quisiera resaltar es cómo la convergencia profunda entre personajes identitarios, arquetípicos, permite reinterpretar el significado del luchador como representante de la cultura mexicana en Australia. Su uso en el anuncio de Doritos tiene sin duda connotaciones discriminatorias, pero la popularidad de los luchadores en otros contextos pudiera conllevar otros valores y establecer conexiones positivas con otras culturas, en este caso con el personaje

\footnotetext{
11 Véase la definición en <http://www.britannica.com/EBche cked/topic/1562158/larrikin>.

12 "The epithet trickster has also been applied to certain popular culture heroes and Euro-American literary characters as well: the romantic outlaw, the con man and particularly the fictional picaro".
} 
del larrikin. Al respecto, encuentro una asociación positiva en el nombre de la cadena de "comida mexicana" Mad Méx, que incluye imágenes de la lucha libre en su escenografía. Su cercanía con el título de la película australiana Mad Max (1979), la popularidad del filme y su identificación con la identidad australiana me permiten reconocer una actitud positiva en el nombre de la taquería y sus asociaciones con la lucha libre. Existen otras convergencias implícitas que, si bien no puedo afirmar que son deliberadas, pudieran servir como puntos de significación compartida. La película se reseña de la siguiente manera en su página oficial:

Mad Max se sitúa en una sociedad distópica del futuro cercano en que se sufre una escasez prolongada de combustible. El orden público se deteriora rápidamente y bandas sin ley perturban el desolado paisaje, desafiando a un ya tambaleante cuerpo policiaco, la Patrulla de Fuerza Central (Mad Max Online). ${ }^{13}$

El héroe de la película, interpretado por el actor australiano Mel Gibson, es representado con la “imagen del larrikin”, que según Krausz (2002: 1) "alcanza su apoteosis con el clásico Mad Max”. ${ }^{14}$ En la película, como en las historias y en las luchas simbólicas representadas por personajes arquetípicos, se pone en juego la legitimidad de las reglas y de los principios de autoridad. Su éxito se basa en la astucia, la creatividad y el cuestionamiento de las fuerzas del poder. Retrata comportamientos comunes que se vinculan con lo que en la investigación de las prácticas informales llamamos The Larrikin Principle. En el contexto de mi argumento lo llamo "estrategias del luchador con principios".

El luchador con principios rompe las reglas y utiliza el engaño para sobrevivir a los peligros del mundo laboral, administrados por jefes intransigentes. Obviamente no todas las prácticas informales son positivas y no todos los lugares de trabajo son

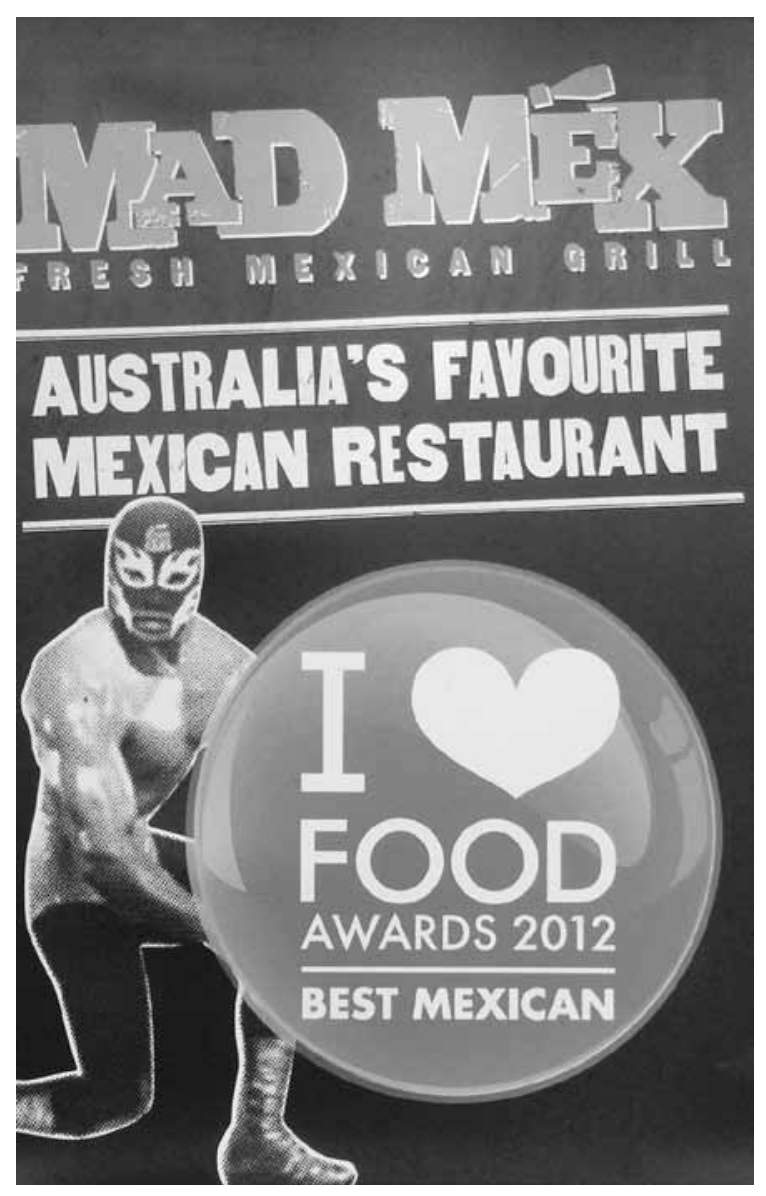

Imagen en la fachada del restaurante Mad Méx.

administrados por normas rígidas. En las historias, versiones esencialistas del larrikin y asociaciones con ilegalidad produjeron rechazo. Sin embargo, hubo un predominio de narradores que identificaban su papel de embaucador como oposición heroica contra el abuso de poder, que hace uso de comportamientos culturales profundos que se manifiestan en

"Mad Max is set in a dystopian near-future society suffering from a prolonged fuel shortage. Civil order is rapidly deteriorating and lawless gangs rampage across the desolate landscape, in defiance of the crumbling police force, the Main Force Patrol".

14 "Reaches its apotheosis with the classic Mad Max". 
sus culturas para resistir las formas de dominación. Los narradores mexicanos establecieron similitudes entre el larrikin australiano y personajes de la cultura mexicana y latinoamericana. Además de los personajes mencionados, aludieron al "Che" Guevara, al subcomandante Marcos y a Frida Kahlo. La representación de estos personajes como el embustero arquetípico, es decir, "incorregible, insaciable, engañoso, cómico y cambiante" (Ballinger, 19911992: 21), ${ }^{15}$ es útil para destacar actitudes y estrategias sintetizadas en dos tendencias comunes:

una actitud particular ante las reglas formales y la autoridad lineal, que ratifica los valores de los sistemas informales, las prácticas flexibles, el igualitarismo, la lealtad a los cuates y la justicia social. El otro es un rechazo del "mierdismo", especialmente cuando emana de las figuras de autoridad y apuntala su ejercicio del poder, perjudicial en las dimensiones importantes del proceso de solidaridad y confianza (Hodge et al., 2010: 229). ${ }^{16}$

Estas tendencias pueden asociarse con la ética igualitaria del Fair Go, considerada fundamental en la identidad australiana (Macintyre, 1999). Los dos principios aparecieron en diferentes formas en las historias y se asociaron con prácticas culturalmente adquiridas en los países de origen, lo que permite sugerir una convergencia a nivel profundo entre culturas, cuando éstas se enfrentan a situaciones adversas e injustificadas, de dominación o abuso de poder.

\section{Conclusión}

Cuando migramos entramos en un proceso de coconstrucción de nuestras identidades. De la misma manera en que las culturas cambian en nuestros países de origen, las culturas con las que nos involucramos en el nuevo entorno están influidas por los intercambios interculturales. Mientras tratamos de manejar las diferencias y las similitudes entre nosotros y otras culturas migrantes en Australia, nuestros comportamientos están en un flujo. En este flujo transformamos nuestras identidades y prácticas culturales y guardamos, hasta cierto punto, un sentido de control cultural sobre lo que adoptamos, cambiamos, mantenemos y cómo lo hacemos. Desde nuestra profundidad cultural nos conectamos con el presente y generamos nuevas formas de vivir nuestras culturas. Seguimos siendo mexicanos o chilenos, argentinos o brasileños, pero de un tipo diferente, más estereotipado. Nos volvemos más latinoamericanos para encajar en el contexto australiano y su imaginario, y de esta manera nos vivimos más "australianos".

En el proceso de re-significación de la profundidad cultural, ya sea mediante representaciones enajenadas, como la de El Macho de Doritos, o bajo el control cultural de sus portadores, como en las prácticas laborales informales, es posible encontrar similitudes entre culturas. El imaginario cultural e identitario del migrante y el del anglosajón australiano, representado por el larrikin y el Fair Go, convergen. Héroes proscritos como el "Che" Guevara, los zapatistas y Ned Kelly se unen como tricksters arquetípicos, luchadores con principios que ayudan a identificarnos con los que rompen las reglas, forajidos o revolucionarios que las sociedades necesitan para prosperar. Al final, más allá de las aparentes diferencias, en nuestras culturas profundas somos un poco embaucadores, cambiamos nuestras prácticas culturales ante la adversidad y usamos nuestras lógicas para adaptarlas a nuevos contextos.

\footnotetext{
"Incorrigible, insatiable, deceptive, comic and transforming". "A distinctive attitude to formal rules and linear authority, affirming the values of informal systems, flexible practices, egalitarianism, loyalty to mates and social justice. The other is a rejection of 'bullshit', especially as it emanates from authority figures and props up their exercise of power, damaging in the process all-important dimensions of solidarity and trust".
} 
Las historias de los embaucadores interculturales, larrikins en Australia, enfatizan la necesidad de incorporar la contribución subyacente de las diferencias culturales para resolver problemas. Desde una perspectiva periférica como migrantes reflexivos, podemos revelar la nueva cultura, cuestionar lo que se considera obvio y contribuir con puntos de vista provenientes de nuestra lógica cultural externa. Esto no significa que otros australianos estén excluidos de esta capacidad. Dada la convergencia cultural profunda compartimos con antiguos o nuevos migrantes, nacidos en Australia o en el extranjero, recursos culturales necesarios para actuar a través del lente del luchador con principios. D

\section{Bibliografía}

Bakhtin, Mikhail M., 1996, The Dialogic Imagination. Four Essays, University of Texas Press (Slavic Series, núm. 1), Austin.

Ballinger, Franchot, 1991-1992, “Ambigere: The Euro-American Picaro and the Native American Trickster”, en mElus, vol. 17, núm. 1: Native American Fiction: Myth and Criticism, pp. 21-23.

Bellanta, Melissa, 2012, Larrikins: A History, University of Queensland Press, St Lucia.

Blue Demon Jr., tienda en línea: <http://www.bluedemonjr.com/tienda.php>, consultado el 24 de mayo de 2013.

Bonfil, Guillermo, 1987a, "La teoría del control cultural en el estudio de procesos étnicos", en Papeles de la Casa Chata, vol. 2, núm. 2, pp. 23-43.

—_, 1987b, México profundo: una civilización negada, Secretaría de Educación Pública, Centro de Investigaciones y Estudios Superiores en Antropología Social, México.

Carro, Nelson, 1984, El cine de luchadores, Filmoteca de la Universidad Nacional Autónoma de México, México.

Castles, Stephen y Elli Vasta, 2004, "Australia: New Conflicts around Old Dilemmas", en Wayne A. Cornelius, Philip L. Martin y James F. Hollifield (eds.), Controlling Immigration: A Global Perspective, Stanford University Press, Stanford.

Cohen, Erez, 2004, “I Am my Own Culture: The 'Individual Migrant' and the 'Migrant Community', a Latin American Case Study in Australia”, en Journal of Intercultural Studies, vol. 25, núm. 2, pp. 123-142.

Coronado, Gabriela, 2003a, “Crossing Borders and Transforming Identities: Encountering Mexicanness in Australia”, en Humanities Research, vol. X, núm. 1, pp. 41-52.

__ 2003b, Las voces silenciadas de la cultura mexicana, Centro de Investigaciones y Estudios Superiores en Antropología Social, México.

—., 2004, "The Intercultural Invention of Authenticity in a Tourist Destination, Cuetzalan, Mexico", en Tourism. An International Interdisciplinary Journal, vol. 52, núm. 2, pp. 131-142.

— Research, vol. 9, núm. 1, pp. 3-17.

__ 2012, "Constructing the 'Neocolonial' Manager. Orientalising Latin America in the Textbooks", en Anshuman Prasad (ed.), Against the Grain: Advances in Postcolonial Organization Studies, Liber, Copenhagen Business School Press, Universitetsforlaget, Copenhague, pp. $160-181$.

Correa, Liliana, 2010, "El lugar de la memoria: Where Memory Lies”, en PORTAL, Journal of Multidisciplinary International Studies, vol. 7, núm. 2, en línea: <http://epress.lib.uts.edu.au/ojs/index.php/portal>.

Doritos, s. f., "Battle of the Flavours", en línea: <http://www.battleoftheflavours.com/lowdown>, consultado el 15 de julio de 2011.

Duarte, Fernanda, 2005, "Living in 'the Betweens': Diaspora Consciousness Formation and Identity among Brazilians in Australia”, en Journal of Intercultural Studies, vol. 26, núm. 4, pp. 315-335.

Ellis, Caroline S. y Arthur P. Bochner, 2000, “Autoethnography, Personal Narrative, Reflexivity: Researcher as Subject”, en Norman K. Denzin e Yvonna S. Lincoln (eds.), The SAGE Handbook of Qualitative Research, SAGE, Thousand Oaks, pp. 733-768.

Encyclopaedia Britannica, 2013, “Larrikin”, en línea: <http://www.britannica.com/EBchecked/topic/1562158/larrikin>, consultado el 15 de mayo de 2013.

Fernández Reyes, Álvaro, 2004, Santo, el Enmascarado de Plata: mito y realidad de un héroe mexicano moderno, El Colegio de Michoacán, Consejo Nacional para la Cultura y las Artes, Zamora.

Geertz, Clifford, 1987, La interpretación de las culturas, Gedisa, Madrid. 
Gumperz, John, [1958] 2009, "The Speech Community”, en Alessandro Durati (ed.), Linguistic Anthropology. A Reader, Blackwell Publishing,

Chichester, pp. 66-73.

Hannerz, Ulf, 1992, Cultural Complexity: Studies in the Social Organization of Meaning, Columbia University Press, Nueva York.

Hijo del Santo, El, El Enmascarado de Plata, tienda en línea: <http://www.elhijodelsanto.com.mx/coffeeshop.html>, consultado el 26 de mayo de 2013.

Hodge, Bob y Gunther Kress, 1993, Language as Ideology, Routledge, Londres.

_ y John O'Carroll, 2006, Borderwork in Multicultural Australia, Allen \& Unwin, Sídney.

_ et al., 2010, Chaos Theory and the Larrikin Principle. Working with Organisations in a Neo-Liberal World, Liber, Copenhagen Business School Press, Copenhague.

Holden, Nigel, 2002, Cross Cultural Management: A Knowledge Management Perspective, Prentice-Hall, Londres.

Holland, Dorothy y Naomi Quinn (eds.), 1987, Cultural Models in Language and Thought, Cambridge University Press, Cambridge.

Jenkins, Richard, 1997, Rethinking Ethnicity: Arguments and Explorations, SAGE, Londres.

Jung, Carl, 2004, On the Nature of Dreams, Scriptor Press, Seattle.

Kramsch, Claire, 2008, Culture and Language, Oxford University Press, Oxford.

Krausz, Peter, 2002, "Australian Identity: A Cinematic Role Call”, en Enhance tv, en línea: <http://enhancetv.com.au/features/english/krausz/ australianidentity.pdf>, consultado el 27 de mayo de 2013

Langer, Beryl, 1990, “From History to Ethnicity: El Salvadoran Refugees in Melbourne”, en Journal of Intercultural Studies, vol. 1, núm. 2, pp. 1-13. Levi, Heather, 2008, The World of Lucha Libre: Secrets, Revelations, and Mexican National Identity, Duke University Press, Durham.

Lévi-Strauss, Claude, 1963, Structural Anthropology, Penguin, Harmondsworth.

Macintyre, Stuart, 1999, A Concise History of Australia, Cambridge University Press, Cambridge.

Mad Max Online, en línea: <http://www.madmaxonline.com/movie-datasheets/>, consultado el 24 de mayo de 2013.

Mego, Andrés, 2007, "Revelaciones de una máscara", en La Tetona de Fellini, en línea: <http://www.tetonadefellini.com/2007/03/los-milagros-de-santo-el-enmascarado-de.html>, consultado el 18 de agosto de 2011.

Online Etymology Dictionary, 2001-2012, The Online Etymology Dictionary, en línea: <http://www.etymonline.com/index.php>, consultado en noviembre de 2011.

Prasad, Anshuman (ed.), 2012, Against the Grain: Advances in Postcolonial Organization Studies, Liber, Copenhagen Business School Press, Universitetsforlaget, Copenhague.

Said, Edward, 1978, Orientalism, Penguin Books, Harmondsworth.

Stratton, Jon y len Ang, 1998, "Multicultural Imagined Communities: Cultural Difference and National Identity in the uSA and Australia", en David Bennett (ed.), Multicultural States: Rethinking Difference and Identity, Routledge, Nueva York, pp. 135-162.

Treffers-Daller, Jeanine, 2009, "Code-switching and Transfer: An Exploration of Similarities and Differences”, en Barbara Bullock y Jacqueline Almeida (eds.), The Cambridge Handbook of Linguistic Code-switching, Cambridge University Press, Cambridge, pp. 58-74.

Vygotsky, Lev, 1978, Thought and Language, mit Press, Cambridge.

Whorf, Benjamin L., 1956, Language, Thought and Reality. Selected Writings, MIT Press, Cambridge. 